\section{Fossil parks}

\section{Angela Milner}

Dinosaurs of the Flaming Cliffs. By Michael Novacek. Anchor: 1996. Pp. 367. $\$ 30$.

Dinosaurs of the East Coast. By David Weishampel and Luther Young. Johns Hopkins University Press: 1996. Pp. 275. $\$ 30$.

The Horned Dinosaurs: A Natural History. By Peter Dodson. Princeton University Press: 1996. Pp. 323. \$35, £23.

HORNED dinosaurs, the east coast of North America and expeditions to Mongolia's Gobi Desert are the subjects of this trio of additions to the ever-growing library of dinosaur books aimed at the general reader. These three fall into the area between primary research literature and textbooks on the one hand, and the popular and glossy 'coffee-table' ware on the other. They are totally different in scope and subject matter, and are written by experts in the field. They cover topics in a depth that would otherwise be difficult for the nonspecialist to access.

The Gobi Desert is one of the two richest and most productive areas for dinosaur fossils in the world, the other being western North America. The spectacular natural treasures of the Gobi were brought to the attention of the world following the American Museum of Natural History's expeditions in the 1920s. Led by Roy Chapman Andrews, the expeditions' goal was to fulfil Henry Fairfield Osborne's hypothesis that our early ancestors lay waiting to be found in central Asia. Instead, they discovered several new dinosaurs and a remarkable series of nests and eggs attributed to the horned dinosaur Protoceratops.

The vertebrate palaeontologists now at the museum took up the challenge where their forebears left off, and in 1989 began a still continuing series of expeditions to the Gobi, organized jointly with the Mongolian Academy of Sciences. In Dinosaurs of the Flaming Cliffs, Michael Novacek, the expedition leader, tells a thoroughly absorbing adventure story, every bit as incident-filled as in Andrews' day, modern conveniences such as satellite navigation notwithstanding. He weaves together the dramas of day-to-day expedition life and the thrill of quite incredible fossil discoveries, with details of scientific methodology, interpretation of the fossil record and palaeoecology, to set the Gobi fauna in the context of Mesozoic evolution.

Some of the fruits of the team's endeavours have already captured the headlines: an Oviraptor preserved on its own nest of eggs, and an Oviraptor embryo. The embryo emerged from an egg type previously confidently assigned to Protoceratops, disproving the identification and interpretation of Oviraptor as a Protoceratops nest-raider and egg-stealer - a belief that had held sway since the expeditions of the 1920s. Novacek discusses the treasures unearthed at the extraordinarily rich fossil site of Ukaa Tolgod, including many exquisitely preserved skulls and skeletons of lizards and of mammals, which are likely to revolutionize our understanding of the history of marsupials and placentals. This eloquent and accessible blend of science and discovery should appeal to a wide readership, scientists and nonscientists alike, and may well inspire the next generation of palaeontologists.

Unlike the Gobi Desert, the east coast of North America is not readily associated with dinosaurs, although it yielded the New World's first discovery, Hadrosaurus foulkii, in 1858, some 16 years after Richard Owen erected Dinosauria based on finds in southern England. The long human association with the dinosaurbearing beds of the eastern seaboard is chronicled by David Weishampel and Luther Young in Dinosaurs of the East Coast. The authors provide a meticulous, well-structured and thoroughly referenced account of 200 years of activities. They cover the collectors, the localities and the material, from many Triassic trackway sites to the challenging array of skeletal fragments and teeth from Jurassic and Cretaceous locations.

East coast dinosaurs are both rare and fragmentary, exposures are few and far between, and cliffs, cuttings and quarries often provide the only collection sites. But the area is as important to our understanding of evolution and palaeobiogeography as richer parts of the world. This book also serves as a field guide, complete with site maps, list of museum displays, sources of information on sites and advice on fossil collecting. Much information has been drawn together to create a comprehensive reference source for eastern North America.

The horned dinosaurs, Ceratopia, never reached eastern North America. The earliest members of the group inhabited Mongolia (as discovered by the Gobi expeditions in the 1920s) and dispersed in the Late Cretaceous period into western North America, which was isolated from the east by the Mid-Continental Sea. Their dispersal and evolution, culminating in Triceratops, is just one of the topics covered by Peter Dodson in The Horned Dinosaurs. A leading specialist on the ceratopians, he stamps authority on his comprehensive review of the past literature and the anatomy, phylogeny and biology of the group.

Dodson combines an easily understood anatomical primer with even-handed treatment of controversial issues, including the unending debate about dinosaur extinction, and distinguishes clearly between facts and speculation. A liberal set of notes covers the text; the qualifiers, extra information and updates add a lot to the value of the whole. This book is ostensibly for the general reader, but also provides a ready up-to-date reference for students and specialists.

Angela Milner is in the Department of Palaeontology, Natural History Museum, Cromwell Road, London SW7 5BD, UK.

\section{New in paperback}

The Race Gallery: The Return of Racial Science by Marek Kohn. Vintage, £6.99. "A useful book... principally about current events rather than being a weighty discussion of underlying issues", Jonathan Marks, Nature 378, 143 (1995).

Ancestral Passions: The Leakey Family and the Quest for Humankind's

Beginnings by Virginia Morell. Simon and Schuster, \$16, £9.99. "Balanced and matter-of-fact", Leslie C. Aiello, Nature 377, 111 (1995).

Bugs in the System: Insects and Their Impact on Human Affairs by May R. Berenbaum. Addison-Wesley, \$15. "The ultimate source of incredible

entomological facts", S. J. Simpson, Nature 374, 842 (1995).

The Chosen Primate: Human Nature and Cultural Diversity by Adam Kuper. Harvard University Press, $\$ 15.95$, £10.50. “An excellent introduction to. an eternally awkward, though fascinating, area of anthropology", Mark Ridley, Nature 369, 110 (1994).

\section{A View to a Death in the Morning:} Hunting and Nature Through History by Matt Cartmill. Harvard University Press, $\$ 15.95$, £10.50. “Elegant, erudite, stimulating", Adam Kuper, Nature 364, 111 (1993).

From Coastal Wilderness to Fruited Plain: A History of Environmental Change in Temperate North America from 1500 to the Present by Gordon G. Whitney. CUP, £19.95. "Whitney's ecological history is as much about our global future as it is about our local past", Stuart L. Pimm, Nature 374, 24 (1995).

Green Imperialism: Colonial Expansion, Tropical Edens and the Origins of Environmentalism 1600-1860 by Richard

H. Grove. CUP, £14.95, \$18.95. “A stimulating, if controversial, source for any ecologist or environmentalist", Quentin Cronk, Nature 376, 652 (1995).

The Day Before Yesterday: Five Million Years of Human History by Colin Tudge. Pimlico, £9.99. "His knowledge of the evolutionary changes in the nonhominid components of the contemporary fauna is impressive", Bernard Wood, Nature 379, 687 (1996). 